\title{
Evaluating the volatilization behavior of PAHs in oil- based residues from drilling cuttings of different thicknesses based on the C-history method
}

Shu Wang

Sichuan University

Jihong Qin

Chengdu University

Bingxin Xie

Sichuan University

Hui Sun ( $\square$ sunhui@scu.edu.cn )

Sichuan University

Xin Li

Sichuan University

\section{Research Article}

Keywords: oil-based residues of drilling cuttings, PAHs, thickness, the C-history method

Posted Date: August 9th, 2021

DOI: https://doi.org/10.21203/rs.3.rs-791410/v1

License: (9) This work is licensed under a Creative Commons Attribution 4.0 International License.

Read Full License 
1 Evaluating the volatilization behavior of PAHs in oil-based residues from

2

3

\title{
drilling cuttings of different thicknesses based on the C-history method
}

\author{
Shu Wang a, Jihong Qin ${ }^{b}$, Bingxin Xie a , Hui Sun ${ }^{a, *}, \mathrm{Xin} \mathrm{Li}^{\mathrm{a}}$ \\ a Department of Environmental Science and Engineering, Sichuan University, Sichuan Research \\ Center for Soil Environment Protection Engineering and Technology, Chengdu 610065, China; \\ b Department of Environmental Engineering, Chengdu University, Chengdu 610106, China. \\ * Corresponding author, sunhuifiles@gmail.com; Tel.: +86-139-8181-5710. \\ E-mail addresses: w.dashu@foxmail.com (S. Wang); qinjihongcdu@foxmail.com (J. Qin); \\ bingxinx@foxmail.com (B. Xie); lixinscu@outlook.com (X. Li).
}

Abstract: Drilling cuttings, the primary byproduct generated from the exploration and mining of shale gas, are potentially hazardous types of waste that seriously deplete land resources and pose environmental safety problems. In this paper, oil-based drilling debris is used as a typical porous medium phase solid waste, and the law and characteristics of unsteady diffusion and release of PAHs are studied under the specific situation of oil-based drilling debris with different thicknesses as the "source". The results showed that(1) Thickness has a greater influence on the diffusion and release law of PAHs from oil-based drilling cuttings residues, the diffusion release of PAHs increases with the increase of sample thickness. (2) The thickness of the porous media source is the main influencing factor of the PAHs diffusion and release diffusion related parameters. The higher the thickness, the diffusion coefficient $D_{m}$ increases with the increase in thickness. The distribution coefficient $K$ and the initial diffusible release concentration $C_{m 0}$ change in a similar manner, and both increase with the thickness.

Keywords: oil-based residues of drilling cuttings; PAHs; thickness; the C-history method

\section{Introduction}

This study by Xiong et al[1] has demonstrated that the proposed C-history method is effective for simultaneously measuring the characteristic emission parameters: the initial emittable concentration, the diffusion coefficient, and the partition coefficient of formaldehyde and VOCs in building materials. By using small scale and full scale chambers, and testing at different 
temperatures, the C-history method is shown to have excellent volume and temperature adaptability. Independent experiments have made the measured parameters in a closed chamber more convincing, and suggest that these parameters can be used to estimate VOC emissons under real conditions. The main advantage of the C-history method is that it is rapid. The proposed C-history method may also be helpful for measuring the characteristic parameters of semivolatile organic compounds (SVOCs) through some improvement[1].

Polycyclic aromatic hydrocarbons (PAHs) are ubiquitous environmental pollutants produced by anthropogenic activities associated with industrialization and urbanization, as well as through natural activities[2]. To date, over 400 kinds of PAHs and their ramifications have been identified[3]. Chemically, PAHs are a group of organic compounds which comprising of two or more benzene rings bonded in linear, cluster,or angular arrangements[4]. It has been proved that PAHs have environmental persistence, bioaccumulation, long-distance migration and high biotoxicity. Meanwhile, PAHs are high melting and boiling points (therefore they are solid), low vapor pressure, and very low aqueous solubility[5,6]. Excessive inhaled or exposed to PAHs, it can cause lung cancer and other adverse reactions[7]. The USEPA has categorized 16 of the PAHs as priority contaminants[8].

In this paper, oil-based drilling debris is used as a typical porous medium phase solid waste, and the law and characteristics of unsteady diffusion and release of PAHs are studied under the specific situation of oil-based drilling debris with different thicknesses as the "source". The purpose of this study is to (1) simulate the diffusion and release characteristics of PAHs in oil-based residues of different thicknesses, and (2) compare and evaluate the diffusion and release characteristics of PAHs in oil-based residues of different thicknesses through the C-history method. It provides scientific data for the diffusion release and characteristic parameters of PAHs in solid waste sources of different thicknesses of porous media, and also provides a scientific basis for the environmental effects and risk management of solid waste sources of porous media during storage, disposal and transportation.

\section{Materials and methods}

\subsection{Materials}


57 cutting manufacturing sites located in southern Sichuan. All samples were dark black powders

58 with a strong diesel odor. After collection, the samples were manually ground with a mortar and

59 pestle and kept in brown wide mouth glass bottles before leaching tests were performed. PAH

60 standards and other relevant solvents were purchased from Chengdu Ke-Long Chemical Regent

61 Co. Some properties of the tested PAHs are listed in Table 1, as well as their concentrations in the

62 oil-based residues. The dichloromethane and methanol were chromatographic grade and used

63 directly without further purification.

64

Table 1 Abbreviations and properties of the polycyclic aromatic hydrocarbons

\begin{tabular}{|c|c|c|}
\hline Compound & Abbreviation & $\begin{array}{l}\text { Concentration } \\
\qquad(\mu \mathrm{g} / \mathrm{kg})\end{array}$ \\
\hline Naphthalene & Nap & 100.05 \\
\hline Acenaphthylene & Acy & 300.68 \\
\hline Acenaphthene & Ace & 2264.58 \\
\hline Fluorene & Flu & 4167.97 \\
\hline Phenanthrene & Phe & 2069.84 \\
\hline Anthracene & Ant & 2988.57 \\
\hline Fluoranthene & Fla & 5712.08 \\
\hline Pyrene & Pyr & 21078.55 \\
\hline Benzo(a) anthracene & $\mathrm{BaA}$ & 2287.42 \\
\hline Chrysene & $\mathrm{Chr}$ & 2326.44 \\
\hline Benzo(b)fluoranthene & $\mathrm{BbF}$ & 3068.45 \\
\hline Benzo(k)fluoranthene & $\mathrm{BkF}$ & 2797.29 \\
\hline Benzo(a) pyrene & $\mathrm{BaP}$ & 457.99 \\
\hline Indeno(1,2,3-cd) pyrene & IcdP & / \\
\hline Dibenzo(a,h) anthracene & DBA & / \\
\hline Benzo(g,h,i) perylene & BghiP & / \\
\hline
\end{tabular}

A closed environment chamber was used to simulate the diffusion and release process of 
PAHs from porous medium solid waste pollution sources in general application scenarios. The experiments simulated the process of oil-based drilling debris residue PAHs entering the ambient air from the inside of the porous medium source from the inside of the reactor to the surface during the general stacking and storage process. The closed environment chamber used in this study was a cube, and to reduce the adsorption/desorption effect of the PAHs on the inner wall of the closed environment chamber, the chamber was made of glass with the inner side polished. This processing allowed the chamber to meet the ASTM standard[9,10]. The length, width and height of the closed environment chamber were each $800 \mathrm{~mm}$; the porous medium solid waste pollution source was placed at the bottom of the closed environment chamber; two air holes were located on the top of the closed environment chamber, and glass plugs were used to block the air holes to ensure the airtightness of the closed environment chamber. During sampling, the glass plugs were removed to connect the sampling tubes. To ensure the airtightness of the entire closed environment chamber, all connections were sealed with polytetrafluoroethylene (PTFE)[11].

\subsection{Closed environment volatilization experiment}

The oil-based residues of shale gas drilling cuttings were tested in this study. To investigate the effect of porous medium source thickness on PAHs diffusion release, oil-based drilling debris residue samples with different thickness were laid at the bottom of the closed chamber device (2 $\mathrm{cm} 、 4 \mathrm{~cm} 、 6 \mathrm{~cm} 、 8 \mathrm{~cm} 、 10 \mathrm{~cm})$. The experimental process in this study lasted for $60 \mathrm{~d}$. An active sampling method with an XAD-2 resin adsorption tube was used to collect the gas from the closed environment chamber. The sampling times were $0.5 \mathrm{~d}, 1 \mathrm{~d}, 2 \mathrm{~d}, 4 \mathrm{~d}, 8 \mathrm{~d}, 12 \mathrm{~d}, 18 \mathrm{~d}, 24 \mathrm{~d}, 30 \mathrm{~d}, 45$ $\mathrm{d}$ and $60 \mathrm{~d}$, and the concentration of PAHs in the gas was measured. During the sampling period, the flow rate was maintained at $500 \mathrm{~mL} / \mathrm{min}$, and sampling continued for $12 \mathrm{~h}$. Because of the large sampling volume, the closed environment chamber was filled according to the same specification; this was used to collect the gas samples at the subsequent sampling time point to eliminate the influence of the sampling process from the same device on the gas component balance in the closed environment chamber.

The XAD-2 resin was removed from the adsorption tube, and $10 \mu \mathrm{L}$ of recovery indicator (2-fluorobiphenyl, p-terphenyl- $\left.\mathrm{D}_{14}\right)$ was added. A fast solvent extraction instrument (BUCHI E-196) was used for extraction with the following parameters: a temperature of $100{ }^{\circ} \mathrm{C}$, pressure of 
120 bar, static extraction time of 5 min, and methylene chloride and n-hexane mixture $(1: 1, V / V)$.

A $20 \mathrm{~mL}$ sample rinse was performed 3 times. After the extract was blow dried with high-purity nitrogen and concentrated to approximately $1 \mathrm{~mL}$, it was passed through a magnesium silicate purification cartridge eluted with dichloromethane and n-hexane in advance with $5 \mathrm{~mL}$ dichloromethane and n-hexane. After the eluent was soaked in the purification column, the control valve was closed and soaked for $2 \mathrm{~min}$. Then, we continued to add $5 \mathrm{~mL}$ of the mixture of methylene chloride and n-hexane and collected all the eluent. The collected eluate was blown with high-purity nitrogen (purity $>99.99 \%$ ) to approximately $0.5 \mathrm{~mL}$, and internal standards (naphthalene- $\mathrm{D}_{8}$, acenaphthene- $\mathrm{D}_{10}$, phenanthrene- $\mathrm{D}_{10}$, chrysene- $\mathrm{D}_{12}$, and perylene- $\mathrm{D}_{12}$ ) were added for determination. The total volume was $1 \mathrm{~mL}$, and the sample was stored at low temperature until testing on the machine.

The 16 organic PAH pollutants produced by oil-based residues of shale gas drilling cuttings were identified and quantified by gas chromatography/mass spectrometry (GC/MS) (GCMS-QP2010 Ultra; Shimadzu, Japan). The GC/MS operational conditions were as follows. The inlet temperature was set at $250^{\circ} \mathrm{C}$, the inlet volume was $1 \mu \mathrm{L}$, and the sample was under splitless mode. The capillary column was an HP-5ms $(30 \mathrm{~m} \times 0.25 \mathrm{~mm} \times 0.25 \mu \mathrm{m})$. The temperature elevation program employed an initial temperature of $70^{\circ} \mathrm{C}$ for 2 min before increasing at $10^{\circ} \mathrm{C} / \mathrm{min}$ to $320^{\circ} \mathrm{C}$ and holding for $5.5 \mathrm{~min}$. The carrier gas was ultrapure helium (99.99\%), and the flow rate was $1 \mathrm{~mL} / \mathrm{min}$. The multiple reaction monitoring (MRM) mode was selected for ion monitoring, and the ionization method was electron impact[12-14].

\subsection{Quality control}

Different quality assurance and control means were applied during sample preparation and chemical analysis, including the use of certified reference materials for instrumental calibration, replicates, reagent blanks, and detection limit verification.

The standards of the 16 organic PAH compounds with 5 internal standards were analyzed in the $1-400 \mu \mathrm{g} / \mathrm{L}$ range to establish standard calibration curves to determine the concentrations of the 16 PAHs collected. All correlation coefficients for the calibration curves were $>0.999$. The method detection limits were $0.82-4.77 \mathrm{ng} / \mathrm{m}^{3}$, as determined by the threefold standard deviation of seven measurements of the lowest concentration of a calibration curve. Blank filters were 
analyzed for each test to estimate any potential contamination. The background value of a blank filter was subtracted from the results for all samples. After sample extraction, the PAHs were analyzed by GC/MS to determine the recovery of the 16 PAHs. The mean recovery for all compounds was $61.23 \%-123.35 \%$.

\subsection{C-history method}

We spread the oil-based residues of drilling cuttings in a closed environment chamber for volatilization. The volatilization process is mainly controlled by the mass transfer process of PAHs from the inside of the oil-based residues of drilling cuttings to the surface. In the volatilization from the surface of oil-based residues of drilling cuttings to the air in a closed environment, the mass transfer process is mainly controlled by a diffusion mechanism. In this study, through the measurement of the time dynamics of PAH volatilization in the oil-based residues of drilling cuttings in a sealed environment, a concentration footprint model was used to fit the volatilization behavior of the PAHs of the samples in a closed environment chamber. We assumed that the oil-based residues were uniform, that the PAH diffusion process inside the oil-based residues was one-dimensional and that the PAHs in the closed environment chamber were well mixed[15,16]. These assumptions have been widely adopted in previous studies. Based on these assumptions, the analytical solution describing PAH emissions are as follows[1,17].

$$
\begin{gathered}
C_{a}(t)=\frac{C_{m 0} \beta}{k \beta+1}+2 C_{m 0} \beta \sum_{n=1}^{\infty} \frac{\sin q_{n}}{q_{n} A_{n}} e^{-D_{m} L^{-2} q_{n}^{2} t} \\
\frac{C_{e q u}-C_{a}(t)}{C_{e q u}}=-2(k \beta+1) \sum_{n=1}^{\infty} \frac{\sin q_{n}}{q_{n} A_{n}} e^{-D_{m} L^{-2} q_{n}^{2} t} \\
\ln \frac{C_{e q u}-C_{a}(t)}{C_{e q u}}=-D_{m} L^{-2} q_{1}^{2} t+\ln \left[-\frac{2(k \beta+1) \sin q_{1}}{q_{1} A_{1}}\right]
\end{gathered}
$$

Equation (3) can then be rewritten as $\ln \frac{C_{e q u}-C_{a}(t)}{C_{e q u}}=S t+I \quad$ (4), where $C_{e q u}=\frac{C_{m 0} \beta}{k \beta+1}, S=$ $-D_{m} L^{-2} q_{1}^{2}, I=\ln \left[-\frac{2(k \beta+1) \sin q_{1}}{q_{1} A_{1}}\right], C_{a}$ is the chamber PAH concentration, $\mu \mathrm{g} / \mathrm{m}^{3} ; C_{m 0}$ is the initial emittable concentration of PAHs in the material, $\mu \mathrm{g} / \mathrm{m}^{3} ; D_{m}$ is the diffusion coefficient of PAHs in the material, $\mathrm{m}^{2} / \mathrm{s} ; k$ is the partition coefficient between the material and air; $L$ is the half thickness of the material, $\mathrm{m}$; and $\mathrm{h}_{\mathrm{m}}$ is the convective mass transfer coefficient, $\mathrm{m} / \mathrm{s} . A_{n}=$ $\left(k \beta-q_{n}^{2} k B i_{m}^{-1}+1\right) \cos q_{n}-q_{n}\left(1+2 k B i_{m}^{-1}\right) \sin q_{n}, \mathrm{n}=1,2, \ldots ; \beta=A L / V ;$ A is the surface area 
of the material (including both surfaces), $\mathrm{m}^{2} ; V$ is the volume of the chamber, $\mathrm{m}^{3}$; and $q_{n}$ represents the positive roots of $\frac{\tan q_{n}}{q_{n}}=\frac{1}{q_{n}^{2} k B i_{m}^{-1}-k \beta} \quad(\mathrm{n}=1,2, \ldots)$.

\section{Results and discussion}

\subsection{Diffusion and release law of PAHs under different thicknesses}

The thickness of the pile represents the absolute content and total release potential of the oil-based drilling debris itself. The results of the diffusion and release law of PAHs from oil-based drilling debris of different thicknesses are shown in Figure 1. For samples with the same particle size, the greater the thickness, the greater the source of pollutants, the higher the absolute content and release potential of the pollutants, and the diffusion of PAHs. The larger the release amount, the easier it is to diffuse and release into the air in a closed environment. Oil-base debris with a particle size of $0.5-2 \mathrm{~mm}$ is selected to fill different heights in a closed environment cell diffusion release experiment. The results show that the diffusion release of PAHs increases with the increase of sample thickness. Compared with other filling thicknesses, The $10 \mathrm{~cm}$ thick oil-based drilling debris has the highest PAHs diffusion release capacity, reaching $4439.32 \mathrm{ng} / \mathrm{m} 3$, which is 1.9 times the thickness of $2 \mathrm{~cm}, 1.8$ times the thickness of $4 \mathrm{~cm}, 1.7$ times the thickness of $6 \mathrm{~cm}$, and 8 $\mathrm{cm} 1.2$ times the thickness. Generally, when the number of pollution sources increases, the initial content of PAHs in the pollution source will increase, which will lead to an increase in the content of PAHs released into the environment by the diffusion of the pollution source. In addition, for a single PAHs, their diffusion release in a closed environment chamber does not completely follow the law of increasing with the increase of thickness. The diffusion release experiment showed a fluctuating trend at the beginning, and when the experiment progressed to the middle and late phases, the diffusion release volume It increases with the increase in thickness.

For oil-based drilling debris with different thicknesses, Nap is the most important PAHs component released, which may be related to Nap having the lowest molecular weight and the highest air diffusion coefficient; followed by Flu and Ace. The diffusion release ability of low-ring PAHs is higher than that of high-ring PAHs. In a closed environment chamber filled with oil-based drilling debris of different thicknesses, although the diffusion and release trends of the main pollutants and a single PAHs are similar, the diffusion release of PAHs is different in the cells of 
different thicknesses. It is related to the amount of oil-based drilling debris in the cell. In addition, we can clearly see that PAHs are released rapidly at the initial stage, and then reach an equilibrium concentration as the diffusion release proceeds to the middle and late stages. However, the difference in thickness results in different time for PAHs to reach equilibrium in a closed environment cell. The smaller the thickness, the earlier the equilibrium will be reached. For example, the two-ring and three-ring Nap, Acy, Ace, and Flu, the closed environment chambers with thicknesses of $2 \mathrm{~cm}, 4 \mathrm{~cm}$ and $6 \mathrm{~cm}$ basically reached a steady state release in the first 12 days, while the closed environment chambers with thicknesses of $8 \mathrm{~cm}$ and $10 \mathrm{~cm}$ The equilibrium concentration is reached in 24 days. For high-ring PAHs, although the thickness is different, there is not much difference in the time to reach the equilibrium concentration.
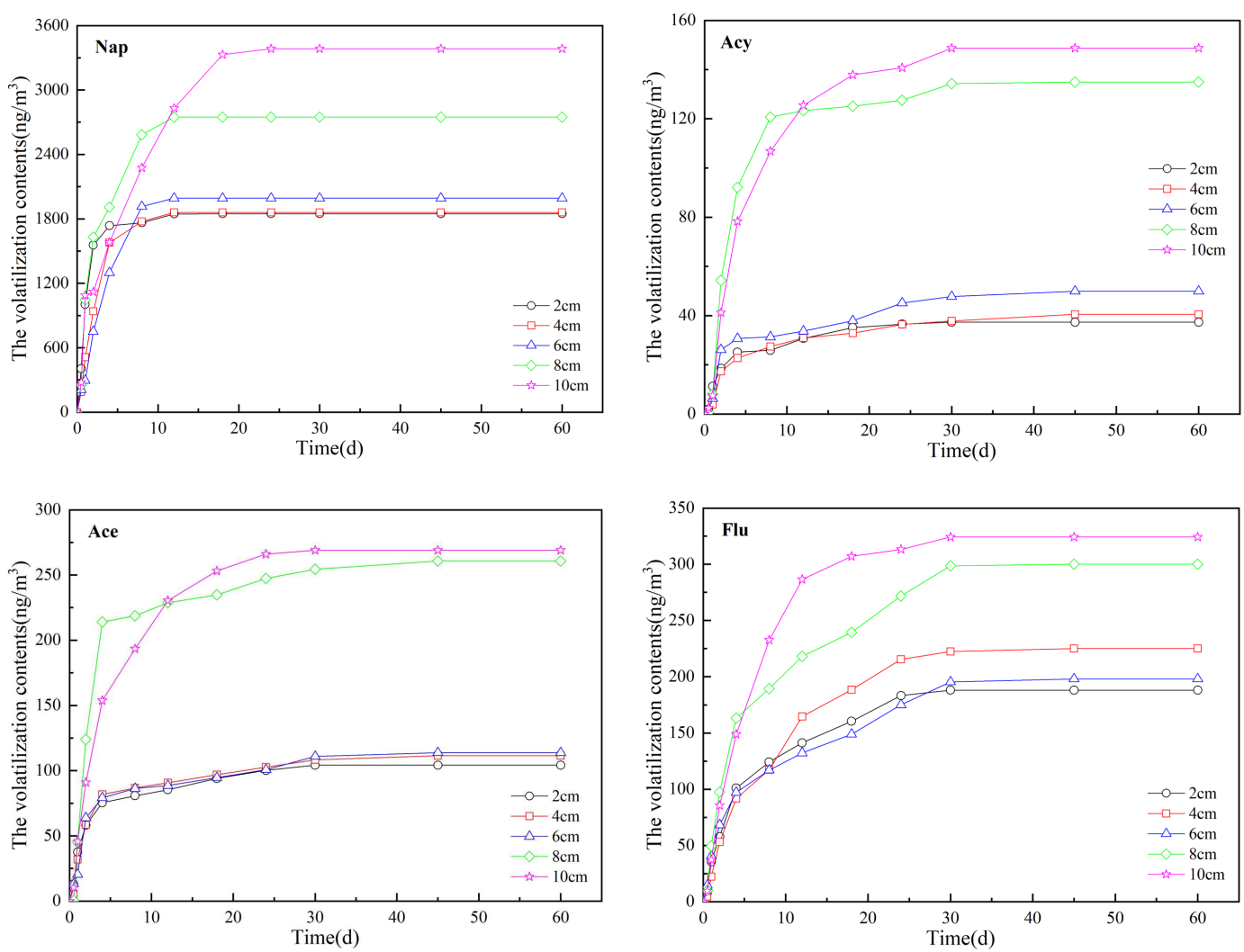

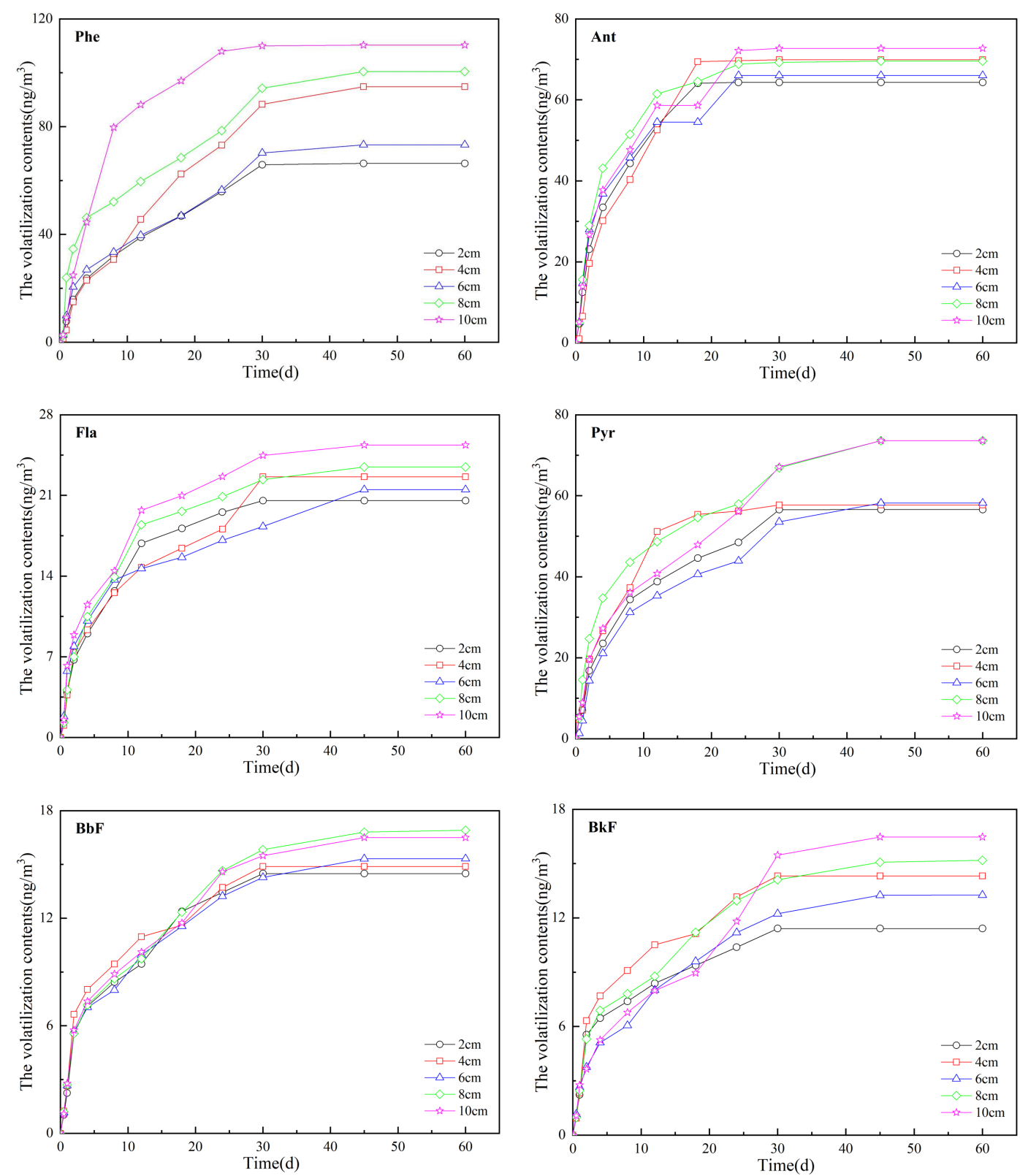

Figure 1 The law of dynamic diffusion release of PAHs from oil-based residues of drilling cuttings with

different thicknesses

3.2 The influence of thickness on PAHs diffusion and release related parameters

\subsubsection{The influence of thickness on the diffusion coefficient $D_{m}$ of PAHs}

The results of PAHs diffusion coefficient $D_{m}$ of oil-based drilling cuttings residues from different thicknesses of porous media were shown in Table 2. It can be seen from the table that the diffusion coefficient $D_{m}$ of all PAHs increases as the thickness of the oil-based drilling debris increases (the magnitude increases from $10^{-6}$ to $10^{-4}$ ), and the thickness can be considered as the diffusion coefficient $D_{m}$ of PAHs The main influencing factors. The increase in the amount of 
oil-based drilling debris will increase the original content of PAHs, which will cause the diffusion coefficient of oil-based drilling debris to increase with the increase in thickness. In addition, the PAHs diffusion coefficient $D_{m}$ of oil-based drilling cuttings residues of different thicknesses has the same trend, that is, the diffusion coefficient of the lower molecular weight PAHs is higher than that of the higher molecular weight PAHs. The most abundant PAHs released by diffusion have lower molecular weight and higher molecular weight. The lighter molecular weight has a lower vapor pressure and a higher air diffusion coefficient resulting in a larger diffusion coefficient.

Table 2 Release constants $D_{m}$ of PAHs from oil-based residues of drilling cuttings with different thicknesses

\begin{tabular}{|c|c|c|c|c|c|}
\hline PAHs & $2 \mathrm{~cm}$ & $4 \mathrm{~cm}$ & $6 \mathrm{~cm}$ & $8 \mathrm{~cm}$ & $10 \mathrm{~cm}$ \\
\hline Nap & $7.87 \times 10^{-6}$ & $3.38 \times 10^{-5}$ & $7.56 \times 10^{-5}$ & $1.58 \times 10^{-4}$ & $1.91 \times 10^{-4}$ \\
\hline Acy & $4.74 \times 10^{-6}$ & $1.77 \times 10^{-5}$ & $4.07 \times 10^{-5}$ & $9.16 \times 10^{-5}$ & $1.21 \times 10^{-4}$ \\
\hline Ace & $8.19 \times 10^{-6}$ & $2.05 \times 10^{-5}$ & $4.57 \times 10^{-5}$ & $7.50 \times 10^{-5}$ & $1.56 \times 10^{-4}$ \\
\hline Flu & $7.26 \times 10^{-6}$ & $2.92 \times 10^{-5}$ & $5.05 \times 10^{-5}$ & $11.93 \times 10^{-5}$ & $1.98 \times 10^{-4}$ \\
\hline Phe & $5.22 \times 10^{-6}$ & $2.07 \times 10^{-5}$ & $4.92 \times 10^{-5}$ & $11.33 \times 10^{-5}$ & $1.57 \times 10^{-4}$ \\
\hline Ant & $5.33 \times 10^{-6}$ & $2.20 \times 10^{-5}$ & $4.99 \times 10^{-5}$ & $9.08 \times 10^{-5}$ & $1.11 \times 10^{-4}$ \\
\hline Fla & $4.71 \times 10^{-6}$ & $1.72 \times 10^{-5}$ & $3.35 \times 10^{-5}$ & $7.57 \times 10^{-5}$ & $1.19 \times 10^{-4}$ \\
\hline Pyr & $7.34 \times 10^{-6}$ & $2.14 \times 10^{-5}$ & $6.01 \times 10^{-5}$ & $5.93 \times 10^{-5}$ & $1.52 \times 10^{-4}$ \\
\hline $\mathrm{BbF}$ & $5.54 \times 10^{-6}$ & $2.16 \times 10^{-5}$ & $3.40 \times 10^{-5}$ & $5.75 \times 10^{-5}$ & $2.16 \times 10^{-4}$ \\
\hline $\mathrm{BkF}$ & $5.73 \times 10^{-6}$ & $1.59 \times 10^{-5}$ & $3.73 \times 10^{-5}$ & $6.69 \times 10^{-5}$ & $1.60 \times 10^{-4}$ \\
\hline
\end{tabular}

\subsubsection{The influence of thickness on the distribution coefficient $K$ of PAHs}

The results of the PAHs distribution coefficient $K$ of the oil-based drilling cuttings residues of different thicknesses were shown in Table 3. It can be seen from the table that the distribution coefficient $K$ of the same type of PAHs in the oil-based drilling cuttings residues of different thicknesses has a certain difference, which is just the opposite of the change law of the diffusion coefficient $D_{m}$. The distribution coefficient $K$ of all PAHs increases with the thickness. Big and reduce. The larger the diffusion coefficient, the smaller the concentration of PAHs staying in the debris of oil-based drilling, and the larger the concentration of PAHs in the air of the closed environment, which leads to the smaller the distribution coefficient.

Table 3 Release constants $K$ of PAHs from oil-based residues of drilling cuttings with different thicknesses 


\begin{tabular}{cccccc}
\hline PAHs & $2 \mathrm{~cm}$ & $4 \mathrm{~cm}$ & $6 \mathrm{~cm}$ & $8 \mathrm{~cm}$ & $10 \mathrm{~cm}$ \\
\hline Nap & 53478.43 & 24891.95 & 16699.52 & 10628.32 & 11015.82 \\
Acy & 36757.11 & 19717.54 & 12837.22 & 7601.47 & 7196.76 \\
Ace & 15913.67 & 12714.53 & 8557.79 & 6958.78 & 4186.17 \\
Flu & 8720.48 & 4328.77 & 3763.15 & 2121.98 & 1596.79 \\
Phe & 4831.92 & 2438.68 & 1538.95 & 891.12 & 801.49 \\
Ant & 6371.20 & 3084.71 & 2041.43 & 1496.07 & 1531.72 \\
Fla & 1719.21 & 938.88 & 724.03 & 427.59 & 339.17 \\
Pyr & 1452.87 & 996.73 & 532.20 & 719.84 & 351.07 \\
BbF & 966.81 & 496.48 & 473.23 & 372.95 & 124.21 \\
BkF & 862.77 & 445.36 & 428.94 & 321.51 & 111.27 \\
\hline
\end{tabular}

3.2.3 The influence of thickness on the initial diffusible release concentration $C_{m 0}$ of PAHs

217 The results of the initial diffusible release concentration $C_{m 0}$ of PAHs in oil-based drilling

218 cuttings residues of different thicknesses were shown in Table 4. The initial diffusible release

219 concentration $C_{m 0}$ of the same PAHs in oil-based drilling cuttings residues at different thicknesses

220 has similar laws. The law is similar to the law of the distribution coefficient $K$ but opposite to the

221 law of the diffusion coefficient $D_{m}$, that is, the initial diffusible release concentration of PAHs

222 decreases as the thickness increases. The larger the diffusion coefficient, the smaller the

223 distribution coefficient, which leads to a decrease in the initial releasable concentration.

224 Table 4 Release constants $C_{m 0}$ of PAHs from oil-based residues of drilling cuttings with different thicknesses

\begin{tabular}{cccccc}
\hline PAHs & $2 \mathrm{~cm}$ & $4 \mathrm{~cm}$ & $6 \mathrm{~cm}$ & $8 \mathrm{~cm}$ & $10 \mathrm{~cm}$ \\
\hline Nap & 98962.84 & 46329.50 & 33276.18 & 29217.88 & 37273.28 \\
Acy & 1470.88 & 799.25 & 640.96 & 1026.30 & 1070.37 \\
Ace & 3137.95 & 1417.56 & 974.59 & 1814.95 & 1126.39 \\
Flu & 2153.07 & 976.48 & 746.48 & 637.91 & 518.62 \\
Phe & 404.13 & 231.94 & 113.11 & 89.84 & 88.71 \\
Ant & 470.73 & 216.16 & 135.13 & 104.33 & 111.58 \\
Fla & 51.49 & 21.39 & 15.68 & 10.12 & 8.68 \\
Pyr & 115.85 & 57.97 & 31.26 & 53.26 & 26.05 \\
\hline
\end{tabular}




\begin{tabular}{cccccc}
\hline PAHs & $2 \mathrm{~cm}$ & $4 \mathrm{~cm}$ & $6 \mathrm{~cm}$ & $8 \mathrm{~cm}$ & $10 \mathrm{~cm}$ \\
\hline $\mathrm{BbF}$ & 15.23 & 7.50 & 7.33 & 6.37 & 2.10 \\
$\mathrm{BkF}$ & 9,88 & 6.63 & 6.56 & 4.92 & 1.88 \\
\hline
\end{tabular}

\subsection{Model theoretical data $\mathcal{E}$ experimental data under different thicknesses}

Thickness is an important factor affecting the diffusion and release of PAHs from oil-based drilling debris. The higher the thickness of oil-based drilling debris in a closed environment cell, the higher the concentration of PAHs in the cell gas. The oil-based drilling debris with thicknesses of $2 \mathrm{~cm}$ and $10 \mathrm{~cm}$ are selected, and the relevant parameters of PAHs diffusion and release are brought into the calculation of the theoretical PAHs concentration value at a certain time under this thickness. As shown in Figure 2, the measured data of PAHs diffusion release in the oil-based drilling cuttings residues of different thicknesses are all within $\pm 20 \%$ of the theoretical concentration error of the model, and the thicknesses are $4 \mathrm{~cm}, 6 \mathrm{~cm}$, and $8 \mathrm{~cm}$. The diffusion and release of PAHs in the oil-based drilling debris are between the theoretical concentration values of the above two thicknesses. The results show that the concentration footprint model can be used to simulate the diffusion and release process of PAHs of oil-based drilling debris with different thicknesses. Knowing the storage height of oil-based drilling debris, we can know the approximate range of PAHs diffusion and release.
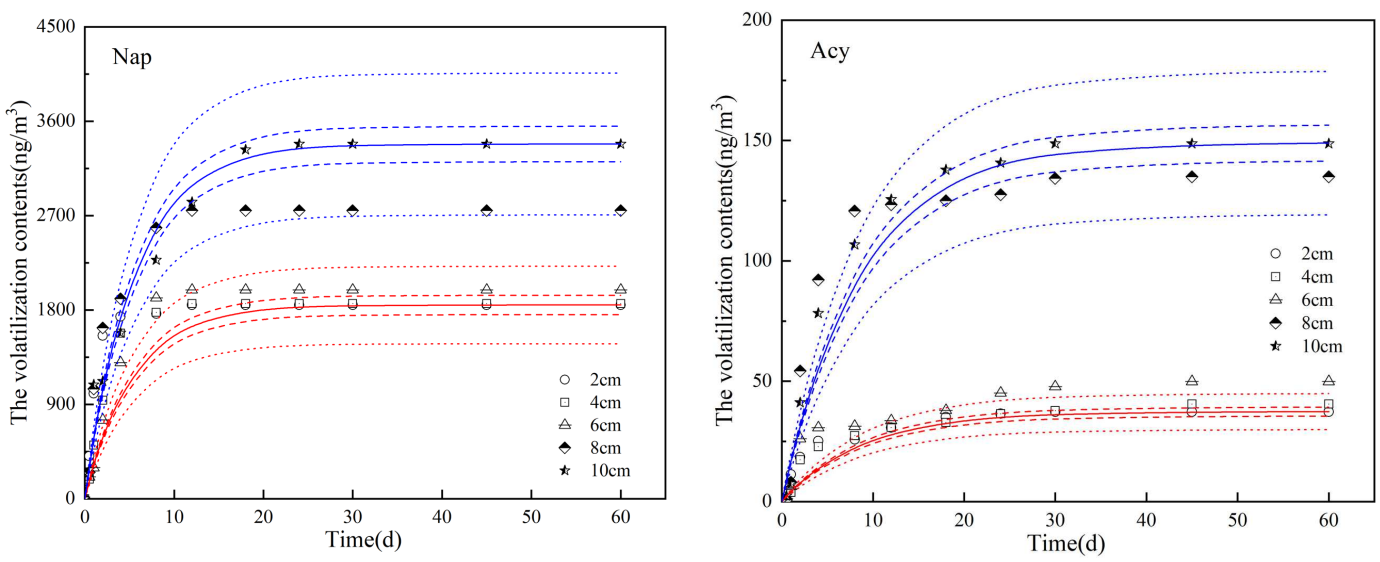

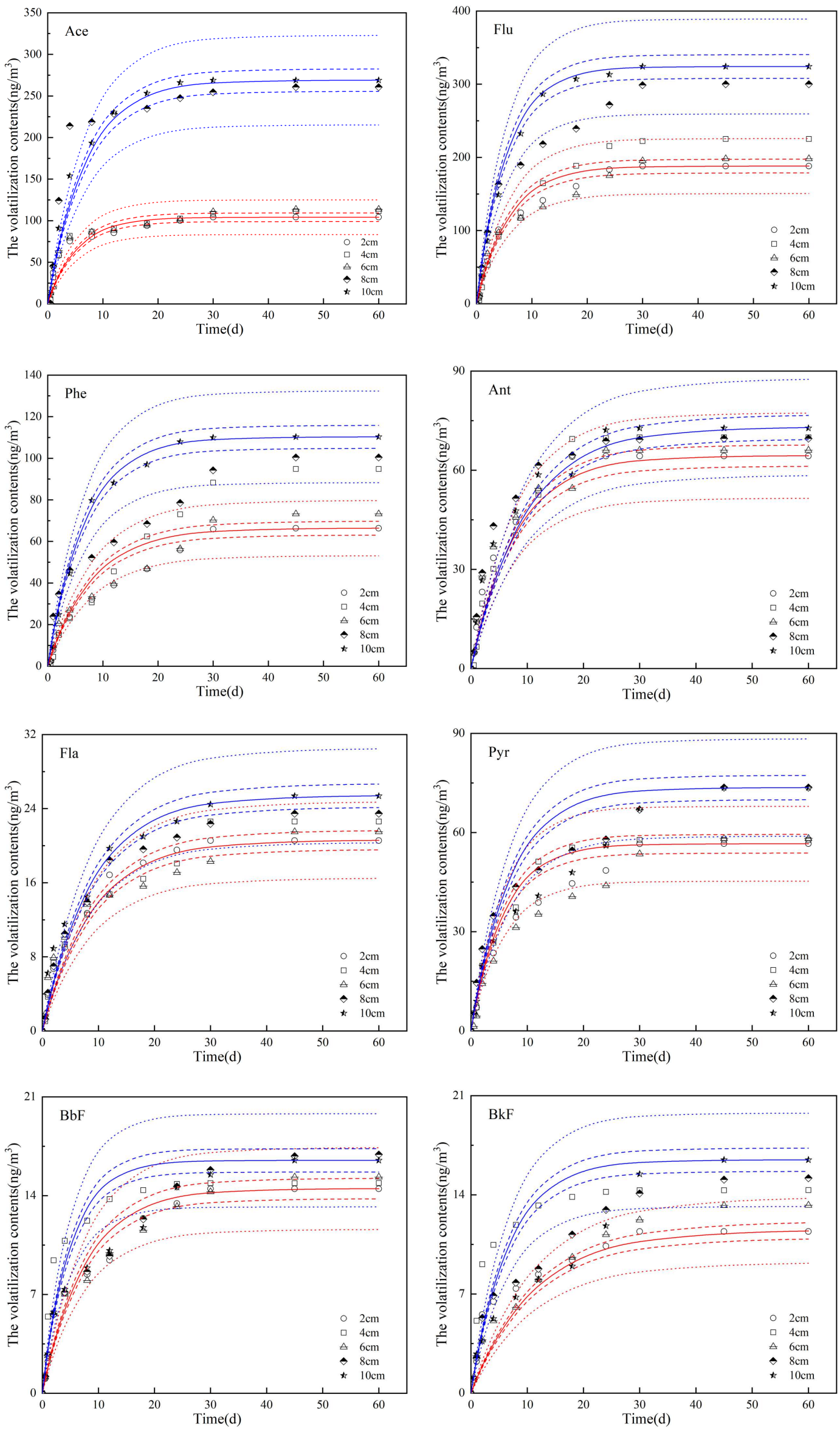
Note: The red line represents the theoretical value of the model with a filling height of $2 \mathrm{~cm}$, the blue line represents the theoretical value

represents $\pm 5 \%$ of the theoretical calculation value of the model. The dotted line represents $\pm 20 \%$ of the theoretical calculation value of

the model.

\section{Conclusions}

The oil-based residue of drill cuttings was investigated and discussed through experiments to assess the potential for the release of dangerous components (PAHs) under specific conditions. Thickness has a greater influence on the diffusion and release law of PAHs from oil-based drilling cuttings residues. For the oil-based drilling cuttings residues of the same particle size, the diffusion release of PAHs increases with the increase of sample thickness. The thickness of the porous media source affects the time for PAHs to reach the equilibrium concentration. The thickness of the oil-based drilling cuttings residues becomes smaller. The sooner PAHs reach the equilibrium concentration. The thickness of the porous media source is the main influencing factor of the PAHs diffusion and release diffusion related parameters. The higher the thickness, the diffusion coefficient Dm increases with the increase in thickness. The distribution coefficient $\mathrm{K}$ and the initial diffusible release concentration $\mathrm{Cm} 0$ change in a similar manner, and both increase with the thickness. The increase and decrease. The increase in thickness leads to an increase in the number of pollution sources, which will also change the initial content of PAHs in the pollution source, which will lead to an increase in the content of PAHs released into the environment by the porous media source.

\section{CRediT authorship contribution statement}

Shu Wang: Investigation, Methodology, Formal analysis, Software, Writing-original draft preparation. Jihong Qin: Validation, Project administration, Conceptualization. Bingxin Xie: Data curation, Validation, Project administration, Conceptualization. Hui Sun: Supervision, Writing-reviewing \& editing. Xin Li: Data curation, Conceptualization. 
The authors declare that they have no known competing financial interests or personal

relationships that could have appeared to influence the work reported in this paper.

269

270

271

272

\section{Acknowledgments}

This work was supported by the National Key Technology R\&D Program of China [No. 2018YFC1900103].

\section{References}

[1] Xiong J, Yao Y, Zhang Y. C-History Method: Rapid Measurement of the Initial Emittable Concentration, Diffusion and Partition Coefficients for Formaldehyde and VOCs in Building Materials[J]. Environmental Science \& Technology. 2011, 45(8): 3584-3590.

[2] Mojiri A, Zhou J L, Ohashi A,et al. Comprehensive review of polycyclic aromatic hydrocarbons in water sources, their effects and treatments[J]. The Science of the Total Environment, 2019, 696:133971.

[3] Pan L Q, Ren J, Jing L. Responses of antioxidant systems and LPO level to benzo(a)pyrene and benzo(k)fluoranthene in the haemolymph of the scallop Chlamys ferrari[J]. Environmental Pollution, 2006, 141(3):443-451.

[4] Pogorzelec M, Piekarska K. Application of semipermeable membrane devices for long-term monitoring of polycyclic aromatic hydrocarbons at various stages of drinking water treatment.[J]. The Science of the Total Environment, 2018, 631-632(AUG.1):1431-1439.

[5] Masih J, Singhvi R, Kumar K, et al. Seasonal Variation and Sources of Polycyclic Aromatic Hydrocarbons (PAHs) in Indoor and Outdoor Air in a Semi Arid Tract of Northern India[J]. Aerosol \& Air Quality Research, 2012, 12(4):515-525.

[6] Abdel-Shafy H I, Mansour M S M. A review on polycyclic aromatic hydrocarbons: Source, environmental impact, effect on human health and remediation[J]. Egyptian Journal of Petroleum, 2016, 25(1): 107-123.

[7] Kim K H, Jahan S A, Kabir E, et al. A review of airborne polycyclic aromatic hydrocarbons (PAHs) and their human health effects[J]. Environment International, 2013, 60(oct.):71-80.

[8] Bojes H K, Pope P G. Characterization of EPA's 16 priority pollutant polycyclic aromatic hydrocarbons (PAHs) in tank bottom solids and associated contaminated soils at oil 
exploration and production sites in Texas.[J]. Regul Toxicol Pharmacol, 2007, 47(3):288-295.

[9] ASTM. Standard Guide for Small-Scale Environmental Chamber Determinations of Organic Emissions From Indoor Materials/Products[J]. West Conshohocken, PA: American Society of Test and Materials, ASTM D5116-17, 2017.

[10] ASTM. Standard Practice for Full-scale Chamber Determination of Volatile Organic Emissions from Indoor Materials/Products[J]. West Conshohocken, PA: American Society of Test and Materials, ASTM D 6670-18, 2018.

[11] Yan W Research on Measurement of Key Parameters and Simulation of VOC Emissions from Building Materials[D]. Master, Tsinghua University, Beijing, 2009.[In Chinese]

[12] Han M, Zhang R, Yu K, et al. Polycyclic aromatic hydrocarbons (PAHs) in Corals of the South China Sea: Occurrence, Distribution, Bioaccumulation, and Considerable Role of Coral Mucus[J]. Journal of Hazardous Materials, 2020, 384(Feb.15):121299.1-121299.8.

[13] HJ646-2013. Ambient air and stationary source emissions-Determination of gas and particl-phase polycyclic aromatic hydrocarbons with gas chromatography/mass spectrometry[S]. Ministry of Ecology and Environmental of the People's Republic of China, 2013.[in Chinese]

[14] Yang T T , Lin S T, Lin T S, et al. Characterization of polycyclic aromatic hydrocarbon emissions in the particulate phase from burning incenses with various atomic hydrogen/carbon ratios[J]. Science of the Total Environment, 2012, 414(none):335-342.

[15] Zhang L Z , Niu J L . Modeling VOCs emissions in a room with a single-zone multi-component multi-layer technique[J]. Building \& Environment, 2004, 39(5):523-531.

[16] Cox S S , Little J C , Hodgson A T . Predicting the Emission Rate of Volatile Organic Compounds from Vinyl Flooring[J]. Environmental Science \& Technology, 2002, 36(4):709-714.

[17] Xiong J , Zhang Y, Huang S . Characterisation of VOC and Formaldehyde Emission from Building Materials in a Static Environmental Chamber: Model Development and Application[J]. Indoor and Built Environment, 2011, 20(2):217-225. 